\title{
The Renewal and Persistence of Group IDENTIFICATION IN AMERICAN POLITICS
}

\author{
Matt A. Barreto and Francisco I. Pedraza \\ Department of Political SCIENCE \\ UNIVERSITY OF WASHINGTON \\ SEATTLE, WA 98195
}

PREPARED FOR PRESENTATION AT:

THE AMERICAN VOTER: CHANGE OR CONTINUITY OVER THE LAST FIFTY YEARS?

THE SHAMBAugh CONFERENCE

UNIVERSITY OF IOWA

MAY 9, 2008 


\section{The Renewal and Persistence of Group Identification in American Politics} Matt A. Barreto and Francisco I. Pedraza, University of Washington

In 1965 Raymond Wolfinger made three important claims in his article, "The development and persistence of ethnic voting," that have not been significantly revisited in 40 years. First, that national origin identification remains salient for members of immigrant groups in America. Second, that ethnic group identity directly influences partisanship "members of an ethnic group show an affinity for one party or the other which can not be explained solely as a result of other demographic characteristics," (896). Third, that the straight line assimilationist theory that ethnic groups eventually shed their ethnic ties is contradicted by the actual evidence. A common finding in the 1960 s was that ethnic identity persisted into the third and fourth generation, contrary to the expectations of sociologist and political scientists. What Wolfinger and others could not have seen coming in 1965 were the new waves of Latin American and Asian immigrants coming to America and creating vibrant new ethnic groups with strong levels of group attachment and identity (indeed, Wolfinger stated, "mass immigration ended fifty years ago"). Since 1965, more than 30 million immigrants have come to America $-85 \%$ of whom are not European - reinvigorating the debate over ethnic group identification and political participation.

Hispanics or Latinos ${ }^{1}$ now represent the largest ethnic minority group in the United States, surpassing Blacks in total population in 2003. The Latino electorate also represents the fastest growing segment of the American vote, increasing by 54\% from 1996 to 2004 and estimated to number 10 million registrants in 2008. Focusing on "old immigrant" groups,

\footnotetext{
${ }^{1}$ In this paper, we use the words Hispanic and Latino interchangeably, and rely on the traditional grouping of Latinos found in social science research. Latinos are those people living permanently in the United States who trace their ancestry to any of the Spanish-speaking countries in Latin America. This obviously excludes persons from Brazil, Haiti, and other non-Spanish speaking countries in Latin America. However, it is also important to note that the category Hispanic or Latino is a self-identifying ethnic group in the U.S. census and most social science surveys.
} 
some scholars have stated that group identity and ethnic coalitions from the New Deal era are dead (Stanley and Niemi 1995; 2006; Waters 1990). In fact, in national elections there is no noticeable gap in the voting patterns of Americans of Italian or Irish descent, and Catholics are among the least cohesive of social groups today in their voting patterns (e.g. table 11.1 in Lewis-Beck et. al. 2008). Given the incredible diversity of the American electorate in 2008, an important question remains: does ethnic group identity influence partisanship, and if it does, how strong or weak is the effect?

Recently, The American Voter Revisited has taken up this precise question of social group identification (chapter 11) in a comparison of six groups in the American electorate. Lewis-Beck and his colleagues examine the group identity and partisan cohesion of African Americans, Women, Jews, Catholics, Union members and Hispanics. In short, they find evidence that social group identity is salient to presidential vote choice: "while different life situations may shape the vote in their own right, they essentially operate independently of group membership, which has an effect unique to itself," (311). However the small sample size of subgroups in the American National Election Study (ANES) and limited questions on group identity prevent a comprehensive analysis or discussion of this topic in The American Voter Revisited, as the authors lament in many parenthetical notes ${ }^{2}$. In particular, Latino or Hispanic Americans are an ideal ethnic group to examine in pursing this question given their size, growth rate, and large immigrant population. Further, the Latino vote has been hotly pursued by both Democratic and Republican Presidential candidates in 2000, 2004, and

\footnotetext{
${ }^{2}$ For example, in explaining Table 11.3 regarding strength of group identity in 2000, the authors note, "unfortunately, this question was not available in the 2004 NES," (312). Later, in explaining why they do not provide results for Hispanics, Blacks, or Jews in Table 11.5 the authors note, "not all of our secondary groups could be examined, because of issues of sample size or cell size. And in one case we had to substitute a feeling thermometer measure because the legitimacy measure was absent," (315).
} 
especially 2008. By many measures, Latinos are the ethnic group of interest in American politics today.

In this paper, we argue that group identification matters to Latinos, and that the ANES significantly underestimates the degree of ethnic identification among Latino registered voters. Despite the increase in interest in Latino voters by scholars and campaign managers, the ANES has provided irreconcilably bad data on the largest minority population in America. The data limitations of the ANES make it difficult at best, and impossible at worst, to say anything about Latino voters vis-à-vis other social groups of voters that scholars have analyzed over the years. In addressing the issue of ethnic group identity and voting among Latinos, it is important first to discuss the methodological issues surrounding the Latino sample in the ANES, and describe the various caution signs, that we think appear around every corner. Next, using the 2006 Latino National Survey (LNS), we explore in detail the degree and influence of ethnic group identity among Latinos. In short, we find that ethnic group identity is much stronger among Latinos than data from the ANES suggests, and that ethnic identification can often be a primary avenue of engaging the political system, often trumping even partisanship. As a result of a large immigrant population, continued and widespread discrimination against Latinos, and new mobilization efforts that encourage ethnic appeals, the Latino electorate embodies the renewal and persistence of group identification in American politics.

While there are several similarities between the immigrant experience at the turn of the century and that of the contemporary wave of Latino immigration, there is at least one important difference that portends major political implications - continued migration flows. It is true that Irish and Italians experienced discrimination in the first half of the twentieth century, and that ethnic voting pattern persisted for some time, as noted by Wolfinger (1965) 
and Parenti (1967). However, Italian and Irish American voters eventually shed their overt group identity in the decades following these observations and became white Americans.

While race is certainly an important factor, a second potential reason is that the number of Irish and Italian immigrants to the United States dropped dramatically by the 1950s, and the flow from these countries became but a trickle of what they once were in the early twentieth century. In stark contrast, the flow of Latino immigrants picked up beginning in the late 1960s and shows little sign of slowing. Not only do racial differences distinguish Mexicans and Puerto Ricans from Irish and Italians, but the large and steady immigration flow of Latinos carries very distinct implications for ethnic group identity many decades into the future.

Thus, it is important to understand the immigrant experience of this new group, Latinos, and the process of political incorporation since the 1970 s, when they replaced European ethnics, as the new "ethnic" group in American politics.

\section{Ethnic Group Politics}

As Lewis-Beck et al (2008) note in their chapter on social group identification, not all group memberships drive political behavior. Individuals can be grouped into objective categories, but membership in such categories does not necessarily lead to distinct political behavior (Huddy 2003). For example, we might group individuals according to gender, and half the population would be said to be a member of the female grouping. Such membership is not likely to translate into individual level politically meaningful behavior, unless that membership is internalized as a collective identity (i.e. feminist). For political scientists, then, the distinction between group membership and group identity is important 
to make because it helps us sort through which social groups we might expect to shape some individual's political behavior, and which ones do not.

The literature points to subjective group identification as the common link between group membership and collective political behavior. Subjective group identification involves an individual integrating membership in a particular group as part of his or her self-identity, and recognizing interdependence in the group (Huddy 2003). This realization of interdependence, also known as linked fate (Dawson 1994), when combined with the desire to address the group's social position through collective action, generates what Miller et al. (1981) call group consciousness. The development of the group consciousness concept has been particularly useful to political scientists because of its application across various kinds of groups, ethnic, racial, economic, dominant and subordinate. Indeed, while Miller et al. (1981) report that the strongest impact of group consciousness on political participation is found among African Americans, there is also evidence that group consciousness is a factor for women, the poor, and businessmen (507). Whatever the group, individual group member awareness of shared interests or a common fate is what seems to matter in order that the potential for cohesive political action be realized.

For our question regarding the persistence and strength of group identity in politics, it is useful to consider the distinction between groups that are formed around voluntary membership, such as unions and Mothers Against Drunk Driving, and those that are ascriptive, such as race and ethnicity. To be clear, both types of groups have the potential to translate identities into political action; however, the factors that contribute to the strength and persistence of group identity seem to favor identities that are ascribed more than those that are acquired (Huddy 2003). Before discussing a key difference between the two groups 
that may account for greater strength and persistence among ascribed identites, it is useful to look at some similarites.

Regardless of whether the identity is ascribed or acquired, the degree to which each group influences members' political outlook depends on how strongly individual members hold the group identity. Normative group beliefs, so the thinking goes, are more likely to be internalized by those that highly value their group memberships (Conover 1984, Tate 1993, Dawson 1994). Yet, the dynamics of an individual's identity and the strength of that identity are not accurately captured by an account that views internalization as a solitary process. Indeed, group identity, by definition, is a social process. To remind us of this point, Uhlaner (1989) provides an important reinterpretation of individual participation in collective action that begins by pointing out that political behavior is a social phenomenon, that is, one that is contextualized by our relationships with others. Part of the social environment includes leadership, and Uhlaner shows how union leaders mobilize members through group loyalty appeals, and how this explains higher rates of turnout. What is recognized by group leaders is that, "[l]oyalty within a group translates into power outside it (Uhlaner 1989:392). Hence, in addition to the strength of identification among individual members, ascriptive and acquired group memberships persist, in part, because leaders use group appeals.

As the research team of The American Voter Revisited acknowledges, the role of elites is important, and "political parties," in particular, "exercise a pivotal role in ensuring this transmission of group distinctivenss, from election to election" (318). Indeed, early research on political parties argued that patronage served the goal of categorizing the electorate in an easy way (i.e. ethnicity), which facilitated later marshalling of votes at election time (Moynihand and Wilson 1906). Parties ensure the role of groups by courting voters as members of groups, and such appeals have long-lasting effects, as evidenced by partisanship 
and party coalition research that shows how changes in group support for parties has been gradual and taken decades to show real dramatic change (Stanley and Niemi 2006). Aside from similarities in terms of the role of leadership and the degree to which individuals value a group identity in explaining the persistence of group political behavior there is one key difference that is highlighted in the race and ethnic group politics research.

Two early pieces connecting ethnic identity and political behavior point out that the development of ethnic politics is partly because of high levels of immigration, residential segregation by national origin group, discrimination and economic exploitation of immigrants by the receiving community (Wolfinger 1965, Parenti 1967). Although Wolfinger (1965) gives a nod to the role of discrimination, his explanation for the persistence of ethnic politics centers on the mobilization of ethnics by political leaders. The persistence of ethnic politics is a matter of "the intensity of ethnic identification and the level of ethnic relevance in the election" (Wolfinger 1965:905, emphasis in the original), and this intensity is communicated to voters most powerfully when they see a co-ethnic on the ballot. By contrast, Parenti (1967) contends that ethnic identity that persists after mainstream acculturation is a function not only of the individual's preference to maintain ties because it helps one know who one is, but it also persists because of discrimination. "Few things so effectively assure the persistence of in-group awareness as out-group rejection, and much of the ethnic cradle-to-grave social structure, often considered 'clannish,' is really defensive” (723).

While Wolfinger (1965), Parenti (1967), Dahl (1961) and others all noted the patterns of "ethnic politics" among European immigrants, few stopped to ask whether the findings were unique, or a general pattern in America. In revisiting the question of ethnic identity, Waters states that "these debates were all based on the assumption - only sometimes made 
explicit - that what happened to white immigrants from Europe would provide a model or a comparison point for the experience of other ethnic and racial groups," (Waters 1990, 6). Twenty-five years after Wolfinger's article, Waters concluded that ethnic identification no longer persisted for European ethnics, and that newer non-white ethnic groups were the important observation groups: "so for all the ways in which I have shown that ethnicity does not matter for white Americans, I could show how it does still matter very much for nonwhites," (Waters 1990, 156).

In their chapter on the role of social groupings Lewis-Beck et. al. (2008) concern themselves principally with measuring the strength of group identification, and are less concerned with their roots. Turning to a discussion on the persistence of group identification in politics, however, prompts us to reflect on these roots. Scholarship on the development and persistence of ethnic/ racial group identity (Wolfinger 1965; Parenti 1967; Miller et al. 1981) suggests three factors will ensure that analysis of political behavior by social groupings will remain a useful approach to studying politics. First, as mentioned above, is the electoral incentive pursued by political elites. Second, in the case of Latinos, the necessary demographic underpinnings of a Latino identity will continue to exist in the United States far into the $21^{\text {st }}$ century. The largest ethnic group in the United States, Latino population growth shows no sign of slowing. Third, it is difficult to characterize the reception of Latinos by the dominant society as welcoming. While the economic opportunities for many Latino immigrants have certainly been better than those available in their country of origin, (and in the case of Cubans in Miami, the motivations were political), for many Latinos, the social experience has been nothing less than rejection, and the political environment has been outright hostile as revealed by the immigration debate since 1990 . 
The discriminatory aspect of the social and political milieu have been shown to have important impacts on the political orientation of Latinos. In summary, we expect strong ethnic identity to persist for Latinos well into the twenty-first century. First, we report strong identification among naturalized Latino citizens, who constitute only a share of the total potential Latino electorate pool, but can be expected to continue being a sizeable block of the total Latino electorate for the next thirty years. Second, many of the Latinos entering politics for the first time since the mid-1990s did so in response to perceived threats (ie CA Proposition 187, 209, 227), and it has been shown that this threat shaped their political orientation, including naturalization rates (Pantoja, Ramirez and Segura 2001), turnout (Pantoja, Ramirez and Segura 2001), political sophistication (Pantoja and Segura 2003), party attachments (Nicholson and Segura 2006), attitudes toward government (Bowler, Nicholson and Segura 2008), and policy preferences (Sanchez 2006; Branton 2007).

The immigrant experience is useful because it allows us to answer questions about political socialization of individuals in a way that is unavailable by examining only native born voters. In particular, this paper will take up the party identification among Latinos across immigrant generation to determine what factors influence their partisanship. Is it socioeconomic status and life cycle factors, or does discrimination, immigration, and social group identification carry more weight in understanding Latino partisan choices? First, it is important to distinguish between Cuban and non-Cuban Latinos when discussing partisanship. Cubans historically demonstrate high rates of Republican affiliation while nonCuban Latinos are just the opposite. Despite these different "choices" we argue that the same factors are at play in influencing Latino party preferences: years lived in the U.S. among immigrants, strength of ethnic identification, and degree of perceived discrimination. We explore the dynamics of social group identity and Latino partisanship using data from the 
2006 LNS, as a way to extend on the analysis by Lewis-Beck et. al. on the importance of social group identity in American politics today.

\section{Latino Ethnic Politics}

In today's political environment, group identification is more relevant than ever before. This is the result of a steady decline in party strength and party machines, and the increase in campaign technology and targeted voter appeals. At the same time that parties were losing their steam, campaigns were finding new ways to compartmentalize the electorate into social groups. Most famously "soccer moms" were a contested group of voters in the 1990s, and many new examples abound. Voter databases and consumer information allow campaigns to directly target groupings of voters with a specific message. All the while, the Latino electorate has been gaining attention each presidential election (de la Garza and DeSipion 2004). The result has been that the typical Spanish surname voter receives an overtly ethnic appeal, in the way of direct mail, phone calls, or knocks on the front door. Campaign materials often appear in Spanish and English, prominent Latino officials endorse the candidate, and immigrant themes are plentiful in campaign ads targeted at Latino households. The result is that Latino voters are constantly reminded of their ethnic identity, in a way that directly connects Latino identity with politics.

In addition to the decline in parties and the rise in micro-targeting, some additional trends, and established findings, lead us to believe that ethnic group identity will remain salient for Latino voters. First, immigration from Latin America continues at a steady pace. This has two immediate effects - one is to grow the Latino population in the United States, bringing more attention (both good and bad) to this minority group. The second is to root the Latino experience in America in the immigrant experience. Already, 60\% of Latino 
adults are foreign born, and about $20 \%$ are second generation with immigrant parents. While Italian and Irish immigration flows were cut off in the 1920s, never to re-appear, this is not the case for Latinos. Next, discrimination against Latinos continues, and anti-immigrant rhetoric and public policy is thriving. The more perceived and real discrimination against a community, the more likely they are to turn to their in-group for support. To this point, Sanchez validates this with public opinion data, and finds exposure to discrimination substantially increases Latino group consciousness (2006).

In particular, when ethnic cues are triggered, such as by a fellow Latino candidate, or harsh rhetoric against immigrants, ethnic identity may be even stronger than other forms of group identity such as partisanship or union membership. Barreto (2007) finds that Republican candidate Orlando Sanchez received a large majority of the Latino vote in the 2001 Houston mayoral election, as did Green Party candidate Matt Gonzalez in San Francisco’s 2003 mayoral election - both running against Democrats. In Los Angeles in 2001, James Hahn received every major union endorsement, yet Antonio Villaraigosa won Latino union members by a 4-to-1 margin according to exit polls.

Finally, Latino voters are much more likely to respond to ethnic campaign appeals. Shaw, de la Garza, and Lee (2000) find Latinos are significantly more likely to vote in the 1996 Presidential election if they received mobilization from a Latino group, as compared to non-Latino groups, or no mobilization at all. Similarly, Ramírez $(2005 ; 2007)$ finds lowpropensity Latino voters respond positively to non-partisan Latino civic groups and behave like high propensity voters. In the 2000 election, DeFrancesco-Soto and Merolla (2006) found that Spanish language campaign commercials had a positive and significant impact on Latino turnout, however English commercials had no effect at all. With regard to vote choice in 2000, Nuño (2007) found that when Latino Republicans canvassed for votes 
among Latino households they successfully increased Bush's vote share. However, when Anglo Republicans contacted Latinos, they drove down votes for Bush. Likewise, when Republican Pete Wilson ran for re-election as California Governor in 1994 endorsing Prop. 187 and using strong anti-immigrant rhetoric the result was Latinos flocking to the Democratic Party (Barreto and Woods 2007). Thus, ethnic identity is, and will remain salient for Latinos vis-à-vis the political system for generations to come.

\section{The ANES Hispanic Sample}

As the number of Latino adult citizens has increased over the past three decades the number of Latino interviews in the ANES has increased from 4\% of all interviews in 1980 to $8 \%$ of all interviews in 2004 . This increase has tempted many scholars to examine and compare Latinos in the ANES with other racial and ethnic groups to better understand political incorporation and participation among Hispanics in the United States. However, there are significant problems with the ANES Hispanic sample that deserve discussion, yet are often relegated to footnotes. Barreto and Segura (2007) have illustrated the deficiencies of the ANES and conclude that data and research on Latinos from 1980 - 2004 is suspect. They point to two important concerns in the current ANES Latino sample which "bias the national sample and dramatically limit the usefulness of the resulting data: the absence of Spanish-language interviews and the small and unrepresentative sub-sample," (Barreto and Segura 2007, 4).

Most critically, the ANES does not translate the survey instrument into Spanish and interviews with Spanish-speaking households are skipped. Approximately $60 \%$ of all Latino adults are foreign-born yet no interviews are conducted in Spanish. Instead, ANES interviewers search for a similarly situated replacement household in which the respondent is 
proficient in English. This introduces an incredible bias by first, excluding Spanish-

dominant households, and second, replacing those individuals with much more assimilated Latino respondents. For almost any dependent variable in Latino politics, the independent variable "Spanish speaker" is statistically significant, yet this half of the Latino population is excluded. ANES interviewers are required to keep careful notes, especially about respondents that decline or terminate interviews. In 2004, $27 \%$ of attempted interviews with Latino households were declined or terminated due to language. Further, some respondents who are included, may actually prefer to answer the 60 minute survey in Spanish. While many immigrants have a good command of conversational English, they may not be prepared to read large portions of English text in the booklet and answer questions in English such as "Where would you place [CANDIDATE] on defense spending? Do you think he wants to greatly increase, somewhat increase..." Thus, it greatly skews the Latino sample towards second and third generation, and the few immigrants who are included are far more assimilated than the typical Latino immigrant.

The second problem Barreto and Segura identified is the small and unrepresentative sample of Hispanics who are included in the ANES. In 1980 only 61 respondents selfidentified as Latino and in 2004 an even 100 Latinos were included. In other years, as the overall sample ANES sample was larger so too was the number of Latinos however it was consistently a very small sample, around $7-8 \%$ of the overall dataset. This is only one problem with the sample, a larger problem is that due to the multi-stage cluster sampling, and a high degree of Latino/non-Latino residential segregation, a great deal of Latinos who are included tend to be picked up in non-Latino neighborhoods. According to Barreto and Segura, "as a consequence of the interaction of the small sample size, the high levels of residential segregation of America in general and Latinos specifically, and the NES sampling 
method, the resulting Latino sample is often bizarrely skewed on geographic and nationalorigin dimensions," $(2007,6)$. For example, in the 2000 ANES 11\% of Latinos were from New York and 3\% were from Florida while in 2004 2\% were from New York and 14\% were from Florida. Given the large differences between Latinos in New York and Florida such changes in the ANES sample make the underlying data unreliable from one year to the next. Similarly, in 2004, only a single Latino respondent was interviewed in Illinois, New Mexico and Arizona combined. Given the unrepresentative nature of the Latino population by state, it is not surprising that the population is also skewed by national origin. In $1984,72 \%$ of Latinos in the ANES were of Mexican origin and in 2000 only $39 \%$ of Latinos were Mexican (in reality $67 \%$ of Latinos were of Mexican origin according to the 2002 CPS). Likewise, Puerto Ricans jump from $20 \%$ of the sample in1980 to $11 \%$ in 1992, a year in which "other" Latinos comprised $45 \%$ of the sample. Finally, there appears to be a significant skew in the age of Latino respondents. Whether it is a result of the English language interviews, limited number of immigrants in the sample, or interviewer bias towards younger respondents, the ANES produced a Latino sample in which $61 \%$ of respondents were age 18-39. In contrast, the Tomás Rivera Policy Institute 2004 national survey of Latino voters found that just 27\% of Latino registered voters were age 18-39, a 34 percentage point discrepancy.

The clear implication is that the Hispanic data collected in the ANES are suspect in any given year, never approaching a representative sample of Hispanic voters. Further, the lack of Spanish surveys introduces a systematic bias in which immigrant, less educated, and less assimilated Latinos are excluded from participation. While the advantage of the ANES is that it provides a national sample of Americans to compare across years, and across subgroups, the Latino subsample in the ANES is so poor that any analysis of the data is unjustifiable. 


\section{Data and Methodology}

For scholars interested in Latino politics, luckily the ANES is not the only source of data. Over the past 20 years, numerous important surveys of Latino voters have been conducted that provide large sample sizes, bilingual interviewers, and nationally representative samples. Among the surveys that are noteworthy are the 1989 Latino National Political Survey (LNPS), the Tomás Rivera Policy Institute (TRPI) surveys 1996 2004, the Pew Hispanic Center surveys 2000 - 2006, and the 2006 Latino National Survey (LNS). Of all the available data, the LNS is the most recent and the most comprehensive in size and scope. Conducted in 2006, the LNS interviewed a total of 8,634 Latino adults in 16 states and asked more than 100 substantive questions (averaging 45 minutes in length). The survey was administered by telephone using bilingual interviewers. Overall, among citizen adults, $41 \%$ of interviews were conducted in Spanish and 59\% in English.

The LNS is an especially appropriate dataset to examine ethnic group identity among Latinos across generation for a couple of reasons. First, because of the large overall sample size, we can reliably distinguish Latinos by four generational groups: first generation immigrants, second generation (US-born with immigrant parents), third generation (US-born with immigrant grandparents), and fourth generation (US-born with US-born parents and US-born grandparents). Second, the LNS contains precise questions on ethnic group identity. Here, we rely on the question, "in general, how strongly or not do you think of yourself as Hispanic or Latino?" with response options very strongly, somewhat strongly, not very strongly and not at all. In addition, the LNS provides an opportunity to measure group identity among Latinos across national origin groups including Mexican, Cuban, Puerto Rican, Dominican, and Salvadoran - the five largest national origin groups. Finally, we can disaggregate the Latino sample by language. Using an index which asked 
respondents to gauge their language abilities in English and Spanish, we classify Latinos as Spanish dominant, English dominant, and bilingual. While the LNS sample frame targeted all Latino adults, in this paper we restrict our analysis to only citizens to match the ANES.

The key dependent variable we are interested in is partisanship, specifically focusing on the degree of partisan agreement among Latinos. While The American Voter Revisited used vote choice in the 2000 and 2004 elections, we detour slightly to focus on partisanship. One advantage the ANES post-election survey has over the LNS is its proximity to the November election, making questions about presidential vote choice ideal. In contrast, the LNS was conducted in the Spring of 2006, 16 months after the 2004 election, introducing recall bias into questions about vote choice in November 2004. Thus, we rely on party identification, a far more stable measure for non-election surveys and still comparable to the vote choice models reported by Lewis-Beck et. al. (2008). We construct party identification using a standard 7-point scale collapsed into three groups: Democrat, Republican, Independent. We group Democratic leaners with Democrats and Republican leaners with Republicans, providing the best metric to calculate the Democrat-Republican gap.

We provide two levels of analysis to explore Latino social group identity and how it effects partisan unity. First, we replicate many of the descriptive tables in The American Voter Revisited, chapter 11, to determine whether or not group identity and group cohesion is stronger or weaker than reported in the ANES data. Second, we rely on multinomial logit to determine the predictors of Latino party identification, specifically with an eye towards generation, language, and ethnic identification. Beyond these independent variables, we also include a host of predictors known to be associated with Latino partisanship: national origin, age, income, education, marital status, religion, gender, years in the U.S., and union membership. 


\section{The Findings}

\section{Descriptive Results}

Focusing on Latino eligible voters, we report several levels of partisan unity, similar to tables created by Lewis-Beck, et. al. (2008, chapter 11). Instead of calculating the difference between the presidential vote for the Democratic minus the Republican, we calculate the partisan divide between Democratic and Republican affiliation. Overall, we find much stronger levels of party unity and ethnic identification among Latinos using the LNS data than reported in the 2000-2004 ANES data.

Table 1 reports the level of Democratic and Republican affiliation among Latinos, including for subgroups by national origin, generation, and language. First, as we note above, it is important to distinguish between Cuban and non-Cuban Latinos given the historic differences in party identification. Table 1 confirms these differences. Among all non-Cuban Latinos, the LNS reports a 42 point advantage for Democratic partisanship, while among Cubans there is a 21 point advantage for Republican partisanship - both groups demonstrating much strong group party unity than the non-Hispanic population. Further, the strong support for the Democratic party is consistent along national origin groups, with Mexicans, Puerto Ricans, Dominicans, and Salvadorans all demonstrating over 40-point partisanship gaps.

Turning to immigrant generation, we find strong partisan unity among Latinos ${ }^{3}$ from first generation immigrants to fourth generation U.S. born. Similar to studies of European ethnic referenced above, we find ethnic party unity into the fourth generation among Latinos. In fact, subsequent generations (third and fourth) demonstrate slightly higher rates of Democratic partisanship than do Latino immigrants. Finally, while some differences

\footnotetext{
${ }^{3}$ Because of the different direction in partisan unity among Cuban and non-Cuban Latinos, we limit the sample to non-Cubans in the generational and language cross-tabs.
} 
emerge due to language, the LNS data establish strong levels of party unity among Latinos who are English dominant, bilingual, or Spanish dominant - though this should not be a surprise given the consistency across generation.

Table 1: Degree of Partisan Unity (replication of Table 11.1 in Lewis-Beck et. al.)

\begin{tabular}{l|ccc}
\hline Group & Dem & Rep & Diff \\
\hline ANES Whites & 41.7 & 49.5 & -7.8 \\
ANES Non-Hispanic & 48.4 & 41.7 & 6.7 \\
All Latinos & 60.5 & 22.6 & 37.9 \\
Non-Cuban & 62.5 & 20.5 & 42.0 \\
Cuban & 32.1 & 53.2 & -21.1 \\
Mexican & 62.5 & 20.4 & 42.1 \\
Puerto Rican & 62.5 & 20.6 & 41.9 \\
Dominican & 68.1 & 10.2 & 57.9 \\
Salvadoran & 62.4 & 19.4 & 43.0 \\
1st Gen & 59.6 & 18.9 & 40.7 \\
2nd Gen & 63.0 & 21.6 & 41.4 \\
3rd Gen & 67.0 & 21.8 & 45.2 \\
4th Gen & 64.6 & 21.3 & 43.3 \\
English & 63.5 & 23.7 & 39.8 \\
Bilingual & 62.7 & 20.9 & 41.8 \\
Spanish & 60.9 & 16.2 & 44.7 \\
\hline \multicolumn{2}{l}{ Source: 2006 Latino National Survey; 2004 ANES }
\end{tabular}

Overall, we find high levels of partisan unity among Latinos, however Lewis-Beck et. al. suggest that degree of group identity may be an intervening variable, and we agree. If there is something unique about Latino identity which promotes Democratic partisanship for non-Cuban Latinos, and Republican partisanship for Cubans, we would expect partisan unity to be even higher for those who more closely invoke their Latino identity. In table 2, we report the rates of ethnic group identity among Latinos and find overall high rates of ethnic identity - about 10 points higher than reported in the ANES data. At the same time, there are interesting differences in the percent of Latinos who selected "very strong" as their ethnic identity across the subgroups reported in table 2. 
Table 2: Strength of Group Identification

(replication of Table 11.4 Lewis-Beck et. al.)

\begin{tabular}{l|ccc|ccc}
\multicolumn{1}{c}{} & \multicolumn{6}{c}{ How strongly or not do you think of yourself as Hispanic or Latino } \\
Group & $\begin{array}{l}\text { Very } \\
\text { Strong }\end{array}$ & $\begin{array}{c}\text { Somewhat } \\
\text { Strong }\end{array}$ & Strong & Not & $\begin{array}{c}\text { Not } \\
\text { very }\end{array}$ & $\begin{array}{l}\text { Not all } \\
\text { Strong }\end{array}$ \\
\hline All Latinos & 64.9 & 25.1 & $\mathbf{( 9 0 . 0 )}$ & 6.4 & 3.7 & $\mathbf{( 1 0 . 1 )}$ \\
Non-Cuban & 65.2 & 25.1 & $\mathbf{( 9 0 . 3 )}$ & 6.2 & 3.5 & $\mathbf{( 9 . 7 )}$ \\
Cuban & 61.0 & 23.9 & $\mathbf{( 8 4 . 9 )}$ & 8.7 & 6.4 & $\mathbf{( 1 5 . 1 )}$ \\
Mexican & 62.8 & 26.9 & $\mathbf{( 8 9 . 7 )}$ & 6.8 & 3.5 & $\mathbf{( 1 0 . 3 )}$ \\
Puerto Rican & 72.9 & 19.0 & $\mathbf{( 9 1 . 9 )}$ & 5.2 & 3.0 & $\mathbf{( 8 . 2 )}$ \\
Dominican & 77.5 & 18.9 & $\mathbf{( 9 6 . 4 )}$ & 2.1 & 1.5 & $\mathbf{( 3 . 6 )}$ \\
Salvadoran & 77.6 & 16.1 & $\mathbf{( 9 3 . 7 )}$ & 6.2 & 0.1 & $\mathbf{( 6 . 3 )}$ \\
1st Gen & 70.5 & 22.1 & $\mathbf{( 9 2 . 6 )}$ & 5.4 & 2.1 & $\mathbf{( 7 . 5 )}$ \\
2nd Gen & 69.1 & 24.5 & $\mathbf{( 9 3 . 6 )}$ & 2.7 & 3.7 & $\mathbf{( 6 . 4 )}$ \\
3rd Gen & 58.4 & 29.5 & $\mathbf{( 8 7 . 9 )}$ & 7.6 & 4.5 & $\mathbf{( 1 2 . 1 )}$ \\
4th Gen & 54.9 & 28.9 & $\mathbf{( 8 3 . 8 )}$ & 10.8 & 5.4 & $\mathbf{( 1 6 . 2 )}$ \\
English & 53.2 & 30.6 & $\mathbf{( 8 3 . 8 )}$ & 10.4 & 5.8 & $\mathbf{( 1 6 . 2 )}$ \\
Bilingual & 70.1 & 22.3 & $\mathbf{( 9 2 . 4 )}$ & 4.5 & 3.2 & $\mathbf{( 7 . 7 )}$ \\
Spanish & 69.4 & 24.1 & $\mathbf{( 9 3 . 5 )}$ & 5.0 & 1.5 & $\mathbf{( 6 . 5 )}$ \\
\hline
\end{tabular}

Source: 2006 Latino National Survey

For non-Cuban Latinos, 90\% stated their Hispanic or Latino identity was strong, and $85 \%$ of Cubans stated it was strong. With respect to generation and language, a predictable pattern emerges that underscores the potential problems in the English-only ANES sample. Among first generation immigrants, $70 \%$ state their ethnic identity is very strong, and the same rate of ethnic identification is found among the second generation. However, third generation Latinos dip to 58\% very strong, and fourth generation register 55\% very strong. Over successive generations, it is fair to say that Latinos do shed some degree of ethnic attachment. At the same time, over $80 \%$ of third and fourth generation Latinos still state their ethnic ID is somewhat or very strong. Language shows a similar pattern with Spanish dominant registering the highest levels of Latino identity (70\% very strong) and English dominant the lowest (53\% very strong). Given these distinctions, we expect that for all Latinos, across national origin, generation, and language, those with higher ethnic identity 
will also demonstrate stronger partisan unity - a similar proposition made by Lewis-Beck et. al. in chapter 11 .

Table 3: Degree of Partisan Unity by Ethnic Identity (replication of Lewis-Beck et. al. Table 11.3)

\begin{tabular}{l|ccc}
\hline & $\begin{array}{c}\text { Strong } \\
\text { Ethnic ID }\end{array}$ & $\begin{array}{c}\text { Weak } \\
\text { Ethnic ID }\end{array}$ & Differential \\
\hline All Latinos & +42.8 & +26.2 & +16.6 \\
Non-Cuban & +46.9 & +29.2 & +17.7 \\
Cuban & -24.0 & -3.6 & -20.4 \\
Mexican & +46.8 & +26.4 & +20.4 \\
Puerto Rican & +47.5 & +39.2 & +8.3 \\
Dominican & $\sim$ & $\sim$ & $\sim$ \\
Salvadoran & $\sim$ & $\sim$ & $\sim$ \\
1st Gen & +43.4 & +28.5 & +14.9 \\
2nd Gen & +44.9 & +23.4 & +21.5 \\
3rd Gen & +53.8 & +34.3 & +19.5 \\
4th Gen & +52.3 & +31.3 & +21.0 \\
English & +55.1 & +23.5 & +31.6 \\
Bilingual & +45.0 & +32.5 & +12.5 \\
Spanish & +43.4 & +37.6 & +5.8 \\
\hline
\end{tabular}

Source: 2006 Latino National Survey

$\sim$ sample size too small for weak ethnic identifiers

Table 3 compares the degree of Democratic unity among Latinos with strong ethnic identity and weak ethnic identity. Non-Cubans with strong ethnic identity register a net Democratic advantage of 46.9 (64.4 D to $17.5 \mathrm{R}$ ) while those with weak ethnic identity show a 29.2 edge (56.1 D to $26.9 \mathrm{R})$ - a gap of about 18 points. Likewise, Cubans with strong ethnic identity are far more likely to be Republicans (-24) than those with weak ethnic identity, where the Republican advantage among Cubans falls to only 3.6. The importance of ethnic identity to partisan unity among Latinos is most noticeable when broken down by generation and language. Among immigrants and Spanish dominant Latinos, the difference between strong and weak ethnic identifiers is less apparent. However, for English dominant and later generation Latinos, having a strong degree of ethnic identification has obvious political implications. English dominant Latinos with high ethnic identity maintain a 55.1 
point Democratic advantage (70.9 D to $15.8 \mathrm{R})$. In contrast, English dominant and weak ethnic identifiers have a 23.5 point Democratic edge (56.0 D to $32.5 \mathrm{R}$ ), a net gap of 31.6 points based on ethnic identity.

\section{Multivariate results}

In addition to the descriptive results, which serve to replicate and extend the analysis by The American Voter Revisited, we are interested in further unraveling the relationship between generation, ethnic identity, and partisanship. In particular, we are curious if the observed interaction between ethnic identity and immigrant generation holds when other correlates and control variable are accounted for. Because of the close relationship between English proficiency and generation, as well as other correlates of acculturation such as educational attainment and income, it is necessary to run multivariate analysis to isolate the effects of generation when controlling for other factors - the tables above do not do this. We used four different regression techniques to assess Latino partisan unity: two different types of dependent variable, and two different approaches to the state-level effects of our 16-state sample. The four variations we include were first, two measures of our dependent variable, partisanship. One version includes Democrats (and leaners) coded as 1, Independents coded as 2, and Republicans (and leaners) coded as 3 and we use multinomial logit to examine predictors of Democratic partisanship. The second version excludes Independents are only focuses on differences between Democratic and Republican identifiers using logistic regression. For both of these dependent variables, we accounted for state-level effects in two different ways. First, we simply include a dummy variable for each of the 16 states in our sample, excluding Florida (the most Republican Latino state) as the comparison group. This approach allows us to independently assess the effects of each state 
in the model alongside our key independent variables, and also effectively controls for the differences in state political culture that are known to influence partisanship. Second, we use a hierarchical linear model in which observations are nested at the state level. Thus, our four estimations are: multinomial logit with state dummies, HLM multinomial logit nested by state, logit with state dummies, HLM logit nested by state. In this paper, we present results and charts based on multinomial logit, with dummy variables for each state, and full results for the other three techniques can be found in the appendix. It should be noted that across all four sets of models the results are nearly identical (thus we are left with the task of deciding which procedure is the most accurate for our data, not which produces the most satisfying results!).

Table 4 contains the regression results and changes in predicted probability for Latino partisanship. Overall, we note many predictable and consistent findings with the literature on Latino partisanship. For example, Cubans are significantly less likely to be Democrats, as compared to Mexican Americans, the excluded national origin group. Women are more Democratic than men, while married couples and home owners are less likely to be Democrats. Catholics and union households are significantly more Democratic. With regard to state, we do find many statistically significant results for the state dummy variables. As compared to Florida, the omitted state, 11 of the 15 remaining states are statistically different with respect to partisanship ${ }^{4}$. While language appeared to have an effect on structuring ethnic identity (table 2 above), with generation and ethnic identity in the model language does not have an independent effect on partisanship.

\footnotetext{
4 These results do not mean that each state is significantly different from all of the rest, only different from Florida. However, when New York is omitted, 12 of the 15 remaining states are statistically different, and when California is omitted 9 of the 15 are different, so we do expect many of the states are indeed statistically unique from most of the other states.
} 
Table 4: Multinomial Logit Regression Results for Latino Partisanship

\begin{tabular}{|c|c|c|c|c|c|c|c|c|}
\hline \multirow[b]{2}{*}{ Independent variable } & \multicolumn{4}{|c|}{ Outcome for Democrat $(y=1)$} & \multicolumn{3}{|c|}{ Outcome for Indep $(y=2)$} & \multirow[b]{2}{*}{$\Delta \mathrm{PP}$} \\
\hline & Coef. & (S.E.) & & $\Delta \mathrm{PP}$ & Coef. & (S.E.) & & \\
\hline Generation & -.2935 & $(.1495)$ & $*$ & -.137 & -.3490 & $(.2142)$ & $\mathrm{t}$ & -.071 \\
\hline Ethnic ID & -.0903 & $(.1095)$ & & & -.1344 & $(.1430)$ & & \\
\hline Generation x Ethnic ID & .1008 & $(.0429)$ & $*$ & .272 & .0590 & $(.0600)$ & & \\
\hline Discrimination & .1517 & $(.0484)$ & ** & .062 & .1749 & $(.0609)$ & $* *$ & .032 \\
\hline Spanish scale & .0300 & $(.0457)$ & & & .1654 & $(.0604)$ & $* *$ & .117 \\
\hline Puerto Rico & -.1294 & $(.1640)$ & & & -.3031 & $(.2041)$ & & \\
\hline Cuba & -1.338 & $(.2044)$ & $* * *$ & -.235 & -1.223 & $(.2579)$ & $* * *$ & -.048 \\
\hline Dominican & .4261 & (.3198) & & & .3092 & $(.3586)$ & & \\
\hline Central America & -.2825 & $(.2051)$ & & & -.4804 & $(.2495)$ & $*$ & -.035 \\
\hline South America & .2667 & $(.2679)$ & & & -.4313 & $(.3392)$ & & \\
\hline Age & .0140 & $(.0029)$ & $* * *$ & .328 & -.0127 & $(.0038)$ & $* * *$ & -.214 \\
\hline Education & .0091 & $(.0144)$ & & & -.0432 & $(.0178)$ & $*$ & -.138 \\
\hline Income & -.0001 & $(.0001)$ & & & $-6.1 \mathrm{E}-6$ & $(3.5 \mathrm{E}-6)$ & $\mathrm{t}$ & -.025 \\
\hline Female & .3704 & $(.0884)$ & $* * *$ & .056 & .3150 & $(.1119)$ & $* *$ & .006 \\
\hline Married & -.1955 & $(.0960)$ & $*$ & -.052 & .0595 & $(.1237)$ & & \\
\hline Home owner & -.3908 & $(.1131)$ & $* * *$ & -.061 & -.2914 & $(.1393)$ & $*$ & .000 \\
\hline Catholic & .4990 & $(.0923)$ & $* * *$ & .104 & .1535 & $(.1159)$ & & \\
\hline Union household & .2971 & $(.1181)$ & ** & .072 & -.0451 & $(.1536)$ & & \\
\hline Arizona & 1.076 & $(.2724)$ & $* * *$ & .191 & .2859 & $(.3393)$ & & \\
\hline Arkansas & .0623 & $(.2929)$ & & & .0253 & $(.3310)$ & & \\
\hline California & .6296 & $(.2043)$ & $* *$ & .144 & -.0700 & $(.2512)$ & & \\
\hline Colorado & .6168 & $(.2551)$ & $*$ & .132 & .0140 & $(.3318)$ & & \\
\hline D.C. metro & .9791 & $(.2720)$ & $* * *$ & .157 & .4778 & $(.3341)$ & & \\
\hline Georgia & .0846 & $(.2751)$ & & & -.5184 & $(.3978)$ & & \\
\hline Illinois & 1.279 & $(.2379)$ & $* * *$ & .216 & .4096 & $(.2863)$ & & \\
\hline Iowa & .6703 & $(.2669)$ & $* *$ & .115 & .3169 & $(.3153)$ & & \\
\hline Nevada & .4249 & $(.2674)$ & & & -.0978 & $(.3353)$ & & \\
\hline New Jersey & .5476 & $(.2175)$ & ** & .123 & -.0479 & $(.2741)$ & & \\
\hline New Mexico & .7350 & $(.2345)$ & $* *$ & .207 & -.8751 & $(.3652)$ & $*$ & -.127 \\
\hline New York & 1.251 & $(.2074)$ & $* * *$ & .218 & .3771 & $(.2586)$ & & \\
\hline North Carolina & .1416 & $(.2929)$ & & & -.3197 & $(.3773)$ & & \\
\hline Texas & .5099 & $(.2109)$ & $*$ & .134 & -.2576 & $(.2699)$ & & \\
\hline Washington & .6182 & $(.2843)$ & $*$ & .055 & .7447 & $(.3214)$ & $*$ & .038 \\
\hline Constant & -.3389 & $(.5546)$ & & .621 & 1.138 & $(.7247)$ & & .161 \\
\hline $\mathrm{N}$ & 3,653 & & & & 3,653 & & & \\
\hline Wald Chi-sq & 487.56 & & & & 487.56 & & & \\
\hline \% Pred Correctly & $62.1 \%$ & & & & $62.1 \%$ & & & \\
\hline Prop Reduction Error & $6.1 \%$ & & & & $6.1 \%$ & & & \\
\hline
\end{tabular}

Note: Basecategory for multinomial logit is Republican $(y=3)$

The independent variables we are most interested in are immigrant generation, ethnic identity, and the interaction between generation and identity. In addition, we expect 
experienced discrimination to also have an important effect by contributing to higher levels of Democratic partisanship.

As the results in table 4 demonstrate, the relationship between generation and ethnic identity is complex. The variable generation is negative and significant suggesting that across generation, Latinos become less Democratic. However, with the interaction term in the model, the direct effect for generation assumes the slope for low-ethnic identifiers across generation. The interaction term generation $x$ ethnic id is positive and significant suggesting that for high ethnic identifiers, Democratic partisanship increases over successive generations in the U.S. This relationship is best expressed in figure 1 below which plots the predicted probability of Democratic partisanship across generation, and accounting for degree of ethnic identity. The top line is for strong ethnic identifiers and increases from a $59.8 \%$ probability of being Democrat in the first generation to $63.6 \%$ in the second generation, $67.1 \%$ in the third generation, and $70.4 \%$ in the fourth generation. In contrast, Latinos with low ethnic identity become less Democratic over generation. As depicted in the bottom line, first generation immigrants with low group id have a $56.4 \%$ probability of being Democrat, compared to 55\% among second generation, $53.1 \%$ in the third generation, and $50.7 \%$ in the fourth generation. We note very little difference between the probability of Democratic partisanship among first generation immigrants based on their degree of ethnic identity, however the gap steadily grows across generation and by the fourth generation a 20 point difference in the probability of being a Democrat exists. (In the logit model when Independents are excluded the results are exactly the same, the only difference being the intercepted about 10-15 points higher towards Democratic partisanship) 


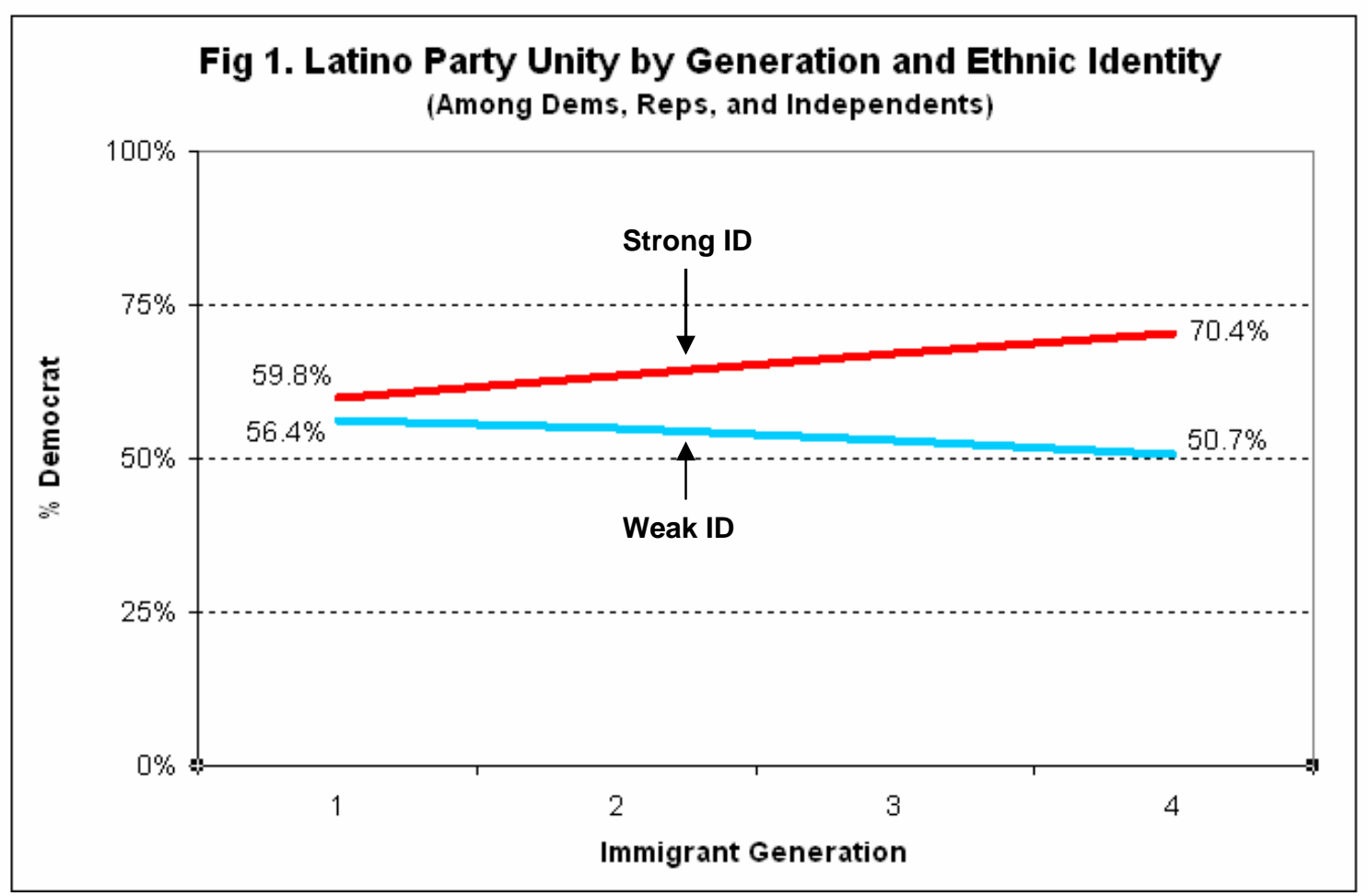

A strong sense of ethnic identity generates not just higher levels of Democratic partisanship, but a much more cohesive political group. The variation around the predicted probabilities for strong id is much tighter than for weak id. Figure 2 adds the bounds of the $95 \%$ confidence interval around each of the point estimates for strong and weak ethnic identity by generation. Most obvious is that the shaded area around the strong id line is more tightly fitted to the line, while considerable variation exists of the weak id line. This demonstrates that, across generation, Latinos with a high degree of ethnic identity are a very cohesive political group. In the fourth generation, $95 \%$ of Latinos with low ethnic identity have between $40 \%$ and $61 \%$ probability of being Democrat. In contrast, $95 \%$ of fourth generation Latinos with high ethnic identity are between $66 \%$ and $74 \%$ likely to be Democrats. 


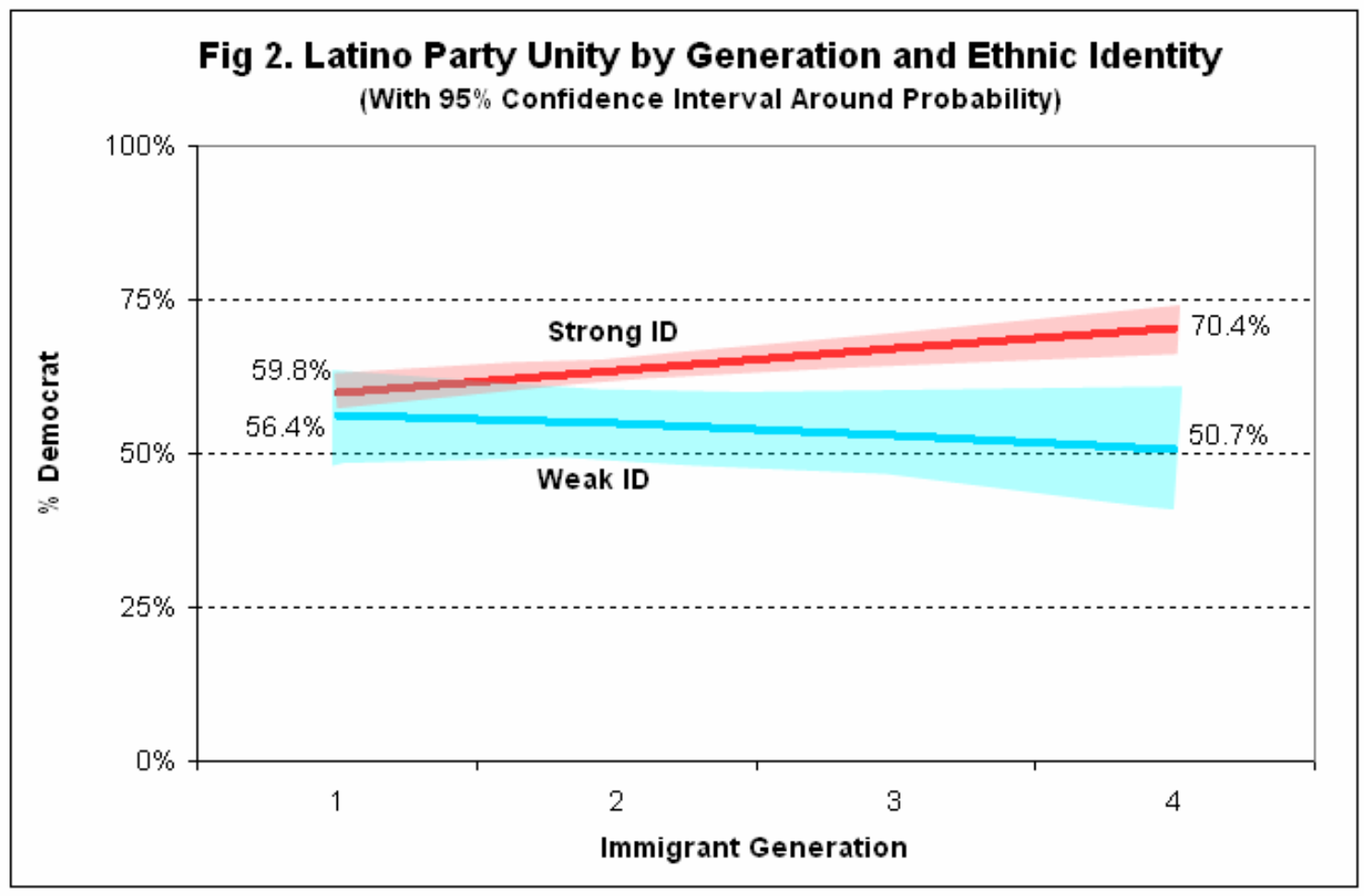

Finally, we find strong evidence that experienced discrimination increases the probability of Democratic partisanship. Latinos who state they have not experienced discrimination across four domains (jobs, police, housing, social) are 6.2\% less likely to be Democrats than those who have experienced in each domain $-60.8 \%$ probability compared to $67.0 \%$. We think there are two factors at play in this relationship. On the one hand, increased perceptions of discrimination against Latinos, and actual experienced discrimination may make Latinos more supportive of the Democratic Party which has historically been associated with antidiscrimination policies and the protection of civil rights. Beyond this direct connection, we may expect that exposure to discrimination increases a sense of group consciousness.

Sanchez finds that Latinos who have experienced discrimination are significantly more likely to believe in concepts such as linked fate and group consciousness, creating an overall heightened sense of ethnic identity. As we observe in figure 1 above, strong ethnic identity 
contributes to Democratic partisanship. Thus, discrimination may have both a direct and indirect influence on Latino partisanship.

Overall, we find high levels of ethnic identity, and high levels of partisan unity among Latinos. Data from the 2006 LNS demonstrate that Latinos maintain a high degree of Democratic partisanship across generation because of the effect of ethnic identity. As Latinos move farther away from the immigrant experience, a strong sense of ethnic identity contributes to increasing group cohesiveness and Democratic partisanship.

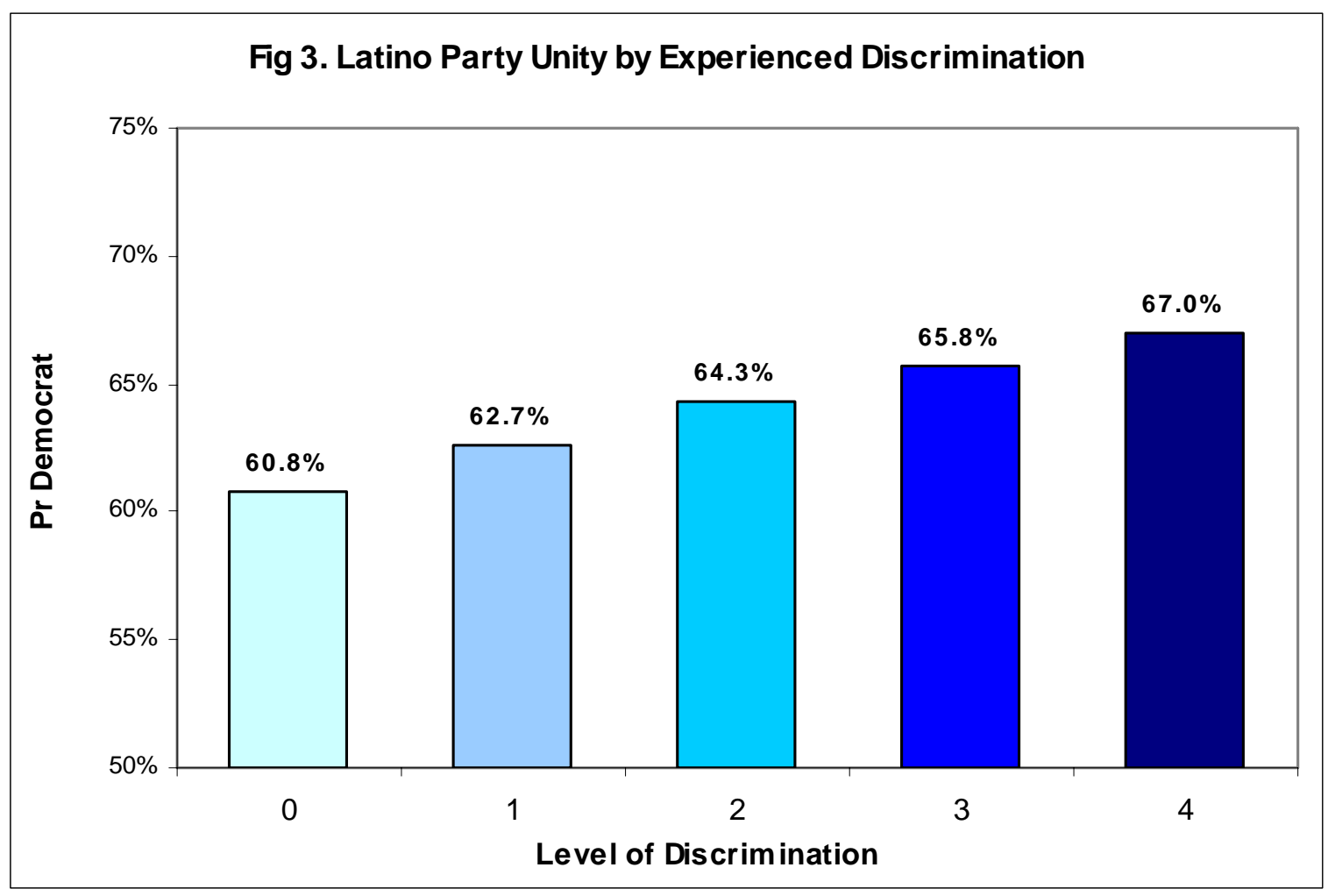




\section{References}

Barreto, Matt A. 2007. "'Si Se Puede! Latino Candidates and the Mobilization of Latino Voters. American Political Science Review. 101(3): 425-442.

Barreto, Matt A. and Gary M. Segura. 2007. "Spanish Translation and Latino Oversample for the American National Election Study." National Science Foundation Research Grant - Social Science Division.

Barreto, Matt and Nathan Woods. 2005. "The Anti-Latino Political Context and its Impact on GOP Detachment and Increasing Latino Voter Turnout in Los Angeles County." In Gary Segura and Shaun Bowler (eds.) Diversity in Democracy: Minority Representation in the United States. Charlottesville: University of Virginia Press.

Bowler, Shaun, Stephen P. Nicholson, and Gary M. Segura. 2006. "Earthquakes and Aftershocks: Tracking Partisan Identification amid California's Changing Political Environment." American Journal of Political Science 50 (January): 146159.

Branton, Regina. 2007. "Latino Attitudes toward Public Policy: The importance of acculturation." Political Research Quarterly 60(2):293-303.

Cain, Bruce E., D. Roderick Kiewiet, and Carole J. Uhlaner. 1989. "The Acquisition of Partisanship by Latinos and Asian-Americans: Immigrants and Native-Born Citizens." American Journal of Political Science. 35(2): 390-422.

Conover, P.J. 1984. "The influence of group identification on political perception and evaluation." Journal of Politics. 46:760-785.

Dahl, Robert A. 1961. Who Governs? New Haven: Yale University Press.

Dawson, M.C. 1994. Behind the Mule: Race and class in African-American politics. Princeton: Princeton University Press.

DeFrancesco Soto, Victoria and Jennifer Merolla. 2006. "Vota por tu Futuro: Partisan Mobilization of Latino Voters in the 2000 Presidential Election." Political Behavior. 28(December): 285-304.

de la Garza, Rodolfo O., and Louis DeSipio, eds. 2004. Muted Voices: Latinos and the 2000 Elections. Lanham, MD: Rowman and Littlefield.

Huddy, Leonie. 2003. "Group Identification and Group Cohesion.” In Oxford Handbook of Political Psychology. David O. Sears, Leonie Huddy, and Robert Jervis, Eds. New York: Oxford University Press.

Lewis-Beck, Michael S., William G. Jacoby, Helmut Norpoth, and Herbert F. Weisberg. 2008. The American Voter Revisited. Ann Arbor, Michigan: University of Michigan Press. 
Miller, Arthur H., P. Gurin, G. Gurin, and O. Malanchuk. 1981. “Group consciousness and political participation. American Journal of Political Science. 25, 494-511.

Nuño, Stephen. 2007. Latino Mobilization and Vote Choice in the 2000 Presidential Election." American Politics Research. 35(March): 273-293.

Pantoja, Adrian D., Ricardo Ramírez and Gary M. Segura. 2001. "Citizens by Choice, Voters by Necessity: Patterns in Political Mobilization by Naturalized Latinos." Political Research Quarterly 54 (December): 729-750.

Pantoja, Adrian D, and Gary M. Segura. 2003. "Fear and Loathing in California: Contextual Threat and Political Sophistication Among Latino Voters." Political Behavior 25 (September): 265-286.

Parenti, Michael. 1967. "Ethnic politics and the persistence of ethnic identification." American Political Science Review. 61(3): 717-726.

Ramírez, Ricardo. 2005. "Giving Voice to Latino Voters: A Field Experiment on the Effectiveness of a National Non-Partisan Mobilization Effort." Annals of the American Political and Social Science. 601:66-84.

Ramírez, Ricardo. 2007. "Segmented Mobilization: Latino Non-Partisan Get Out the Vote Efforts in the 2000 General Election." American Politics Research. 35(March): 155-175.

Sanchez, Gabriel. 2006. The Political Role of Group Consciousness in Latino Public Opinion. Political Research Quarterly. 59(3):435-446.

Shaw, Daron, Rodolfo de la Garza, and Johgho Lee. 2000. "Examining Latino Turnout in 1996: A Three-State, Validated Survey Approach." American Journal of Political Science. 44(2): 338-46.

Stanley, Harold W., and Richard G. Niemi. 1995. "The Demise of the New Deal Coalition: Partisanship and Group Support, 1952-1992.” In Democracy's Feast: Elections in America, ed. Herbert F. Weisberg. Chatham, NJ: Chatham House. 220-40.

Stanley, Harold W., and Richard G. Niemi. 2006. "Partisanship, Party Coalitions, and Group Support, 1952-2004.” Presidential Studies Quarterly. 36(June): 172-188.

Tate, Katherine. 1993. From protest to politics: The new black voters in American elections. New York: Russell Sage.

Uhlaner, Carole J, Bruce E. Cain, and D. Roderick Kiewiet. 1989. "Political Participation of Ethnic Minorities in the 1980's." Political Behavior. 11(3): 195-231 
Uhlaner, Carole J. 1989. "Rational Turnout: The Neglected Role of Groups." American Journal of Political Science. 33(2):390-422.

Waters, Mary C. 1990. Ethnic Options: Choosing Identities in America. Berkeley: University of California Press.

Wolfinger, Raymond E. 1965 "The Development and Persistence of Ethnic Voting" American Political Science Review. 59(4): 896-908. 


\section{Appendix: Replication of Models}

Replication of model with dichotomous dependent variable Dep var is partisanship, $0=$ Rep $1=$ Dem

\begin{tabular}{|c|c|c|c|}
\hline Generation & $\begin{array}{l}\text { Coef. } \\
-0.2730\end{array}$ & $\begin{array}{r}\text { Std. Err. } \\
0.1613 \\
\end{array}$ & $\begin{array}{l}\mathrm{P}>|\mathrm{z}| \\
\mathrm{t}\end{array}$ \\
\hline Ethnic ID & -0.0611 & 0.1130 & \\
\hline Generation x Ethnic ID & 0.0953 & 0.0446 & * \\
\hline Discrimination & 0.1538 & 0.0487 & $\star *$ \\
\hline Spanish scale & 0.0283 & 0.0470 & \\
\hline Puerto Rico & -0.0994 & 0.1633 & \\
\hline Cuba & -1.3333 & 0.2045 & $\star \star \star *$ \\
\hline Dominican & 0.4518 & 0.3229 & \\
\hline Central America & -0.2657 & 0.2057 & \\
\hline South America & 0.3422 & 0.2700 & \\
\hline Age & 0.0141 & 0.0030 & $* * *$ \\
\hline Education & 0.0076 & 0.0150 & \\
\hline Income & 0.0000 & 0.0000 & \\
\hline Female & 0.3942 & 0.0891 & $\star \star \star *$ \\
\hline Married & -0.1978 & 0.0976 & * \\
\hline Home owner & -0.3997 & 0.1151 & $\star \star \star *$ \\
\hline Catholic & 0.5091 & 0.0931 & $\star \star *$ \\
\hline Union household & 0.3217 & 0.1188 & $\star *$ \\
\hline Arizona & 1.0928 & 0.2748 & $\star * *$ \\
\hline Arkansas & 0.0669 & 0.2940 & \\
\hline California & 0.6510 & 0.2044 & $* * *$ \\
\hline Colorado & 0.6310 & 0.2580 & * \\
\hline D.C. metro & 0.9503 & 0.2752 & $* * *$ \\
\hline Georgia & 0.0325 & 0.2779 & \\
\hline Illinois & 1.2713 & 0.2380 & $\star \star \star *$ \\
\hline lowa & 0.7328 & 0.2675 & $* *$ \\
\hline Nevada & 0.4636 & 0.2711 & $\mathrm{t}$ \\
\hline New Jersey & 0.5278 & 0.2193 & * \\
\hline New Mexico & 0.7561 & 0.2372 & $\star \star * *$ \\
\hline New York & 1.2290 & 0.2081 & $\star \star *$ \\
\hline North Carolina & 0.0984 & 0.2921 & \\
\hline Texas & 0.5249 & 0.2126 & * \\
\hline Washington & 0.5573 & 0.2856 & * \\
\hline Constant & -0.4552 & 0.5693 & \\
\hline
\end{tabular}


Appendix

Replication of multinomial logit model with hierarchical linear model, nested by state Dep var is partisanship, $1=$ Dem $2=$ Ind $3=$ Rep, basecategory is Rep

\begin{tabular}{|c|c|c|c|c|c|c|}
\hline & \multicolumn{3}{|c|}{ Democrat $(y=1)$} & \multicolumn{3}{|c|}{ Independent $(y=2)$} \\
\hline & Coef. & Std Err & $\mathrm{P}>|\mathrm{z}|$ & Coef. & Std Err & $\mathrm{P}>|\mathrm{z}|$ \\
\hline Generation & -0.2714 & 0.1587 & $\mathrm{t}$ & -0.3530 & 0.2113 & $\mathrm{t}$ \\
\hline Ethnic ID & -0.0748 & 0.1121 & & -0.1276 & 0.1380 & \\
\hline Generation $x$ Ethnic ID & 0.0962 & 0.0443 & * & 0.0495 & 0.0592 & \\
\hline Discrimination & 0.1545 & 0.0469 & $\star * *$ & 0.1790 & 0.0587 & ** \\
\hline Spanish scale & 0.0362 & 0.0447 & & 0.1549 & 0.0576 & $\star *$ \\
\hline Puerto Rico & -0.1483 & 0.1379 & & -0.2553 & 0.1701 & \\
\hline Cuba & -1.4597 & 0.1765 & $\star \star \star$ & -0.9954 & 0.2237 & $\star \star \star$ \\
\hline Dominican & 0.4174 & 0.2916 & & 0.3635 & 0.3310 & \\
\hline Central America & -0.3021 & 0.1975 & & -0.4062 & 0.2424 & $\mathrm{t}$ \\
\hline South America & 0.2274 & 0.2360 & & -0.3258 & 0.3105 & \\
\hline Age & 0.0143 & 0.0029 & $\star \star \star$ & -0.0137 & 0.0038 & $\star \star \star$ \\
\hline Education & 0.0070 & 0.0143 & & -0.0448 & 0.0174 & ** \\
\hline Income & 0.0000 & 0.0000 & & 0.0000 & 0.0000 & $\mathrm{t}$ \\
\hline Female & 0.3839 & 0.0879 & $\star \star \star$ & 0.3135 & 0.1122 & $\star \star$ \\
\hline Married & -0.2252 & 0.0957 & * & 0.0774 & 0.1219 & \\
\hline Home owner & -0.4142 & 0.1098 & $\star \star \star$ & -0.2745 & 0.1347 & * \\
\hline Catholic & 0.5114 & 0.0909 & $\star * *$ & 0.1509 & 0.1156 & \\
\hline Union household & 0.3433 & 0.1154 & $\star \star$ & -0.0528 & 0.1540 & \\
\hline Constant & 0.2603 & 0.5388 & & 1.3055 & 0.6708 & * \\
\hline \multicolumn{7}{|c|}{ Variances and Covariances of random effects } \\
\hline Level 2: state & 0.0801 & 0.0329 & ** & & & \\
\hline
\end{tabular}


Appendix

Replication of logit model with hierarchical linear model, nested by state Dep var is partisanship, $0=\operatorname{Rep} 1=$ Dem

\begin{tabular}{|c|c|c|c|}
\hline & Coef. & Std. Err. & $P>|z|$ \\
\hline Generation & -0.2745 & 0.1632 & $\mathrm{t}$ \\
\hline Ethnic ID & -0.0611 & 0.1152 & \\
\hline Generation x Ethnic ID & 0.0957 & 0.0455 & * \\
\hline Discrimination & 0.1546 & 0.0473 & $\star \star \star *$ \\
\hline Spanish scale & 0.0229 & 0.0455 & \\
\hline Puerto Rico & -0.1183 & 0.1298 & \\
\hline Cuba & -1.3896 & 0.1738 & $* * *$ \\
\hline Dominican & 0.4223 & 0.2885 & \\
\hline Central America & -0.2553 & 0.2028 & \\
\hline South America & 0.3337 & 0.2386 & \\
\hline Age & 0.0141 & 0.0030 & $\star \star \star \star ~$ \\
\hline Education & 0.0074 & 0.0147 & \\
\hline Income & 0.0000 & 0.0000 & \\
\hline Female & 0.3949 & 0.0890 & $\star \star \star *$ \\
\hline Married & -0.2072 & 0.0971 & * \\
\hline Home owner & -0.4041 & 0.1106 & $\star * *$ \\
\hline Catholic & 0.5109 & 0.0922 & $\star \star \star *$ \\
\hline Union household & 0.3331 & 0.1163 & ** \\
\hline Constant & -0.0760 & 0.5510 & \\
\hline \multicolumn{4}{|c|}{ Variances and covariances of random effects } \\
\hline Level 2: state & 0.2594 & 0.0828 & ** \\
\hline
\end{tabular}

